\title{
COMPARISON OF SERUM MAGNESIUM AND TROPONIN-T IN ACUTE CORONARY SYNDROME
}

Ajay Kumar ${ }^{1}$, Shaveta Sagar ${ }^{2}$

\section{HOW TO CITE THIS ARTICLE:}

Ajay Kumar, Shaveta Sagar. "Comparison of serum magnesium and Troponin-T in acute coronary syndrome". Journal of Evolution of Medical and Dental Sciences 2013; Vol2, Issue 30, July 29; Page: 55655567.

\begin{abstract}
Magnesium, the fourth most common cation in the body, has been the recent focus of much clinical and scholarly interest. Magnesium in coronary artery disease is reviewed with regard to its role in the pathogenesis of arteriosclerosis, coronary spasm, myocardial function, acute myocardial infarction and ventricular arrhythmias. Coronary occlusion in a previously magnesium-depleted heart will result in a larger area of necrosis and ischaemia. Troponin $\mathrm{T}$ is used as a marker for myocardial infarction and its serum value is directly proportional to area of infarction. To elucidate the relationship between magnesium levels and area of infarction we compared serum levels of magnesium and Troponin $\mathrm{T}$ in patients admitted with Acute Coronary Syndrome. Forty one patients diagnosed with Acute Coronary Syndrome for whom serum magnesium and Troponin $\mathrm{T}$ was requested on the day of admission were taken into the study. Serum magnesium correlated negatively with serum Troponin $\mathrm{T}$ (Pearson correlation coefficient ' $r$ ' is -0.022). The negative correlation between serum magnesium and Troponin $T$ shown by current study could mean low serum magnesium values may have higher area of infarction. This may be indirectly due to the fact that magnesium is associated with higher severity of comorbid states such as dyslipidemia, insulin resistance, poor glycemic control and affected carbohydrate metabolism. The strength of correlation shown by present study is very weak. Hence, further studies are required to arrive at a definitive conclusion.
\end{abstract}

KEY WORDS: magnesium, troponin T, acute coronary syndrome, infarction

INTRODUCTION: Magnesium, the fourth most common cation in the body, has been the recent focus of much clinical and scholarly interest. Previously underappreciated, this ion is now established as a central electrolyte in a large number of cellular metabolic reactions (1). Magnesium is a cofactor in more than 300 cellular enzymatic systems and has a key role in cellular metabolism, the recognition that Mg deficiency or excess may be associated with significant clinical consequences has resulted in an increased interest in the utility of serum $\mathrm{Mg}$ measurement ( ). Magnesium is an important intracellular cation that is distributed into three major compartments: mineral phase of bones (65\%), intracellular space (34\%) and extracellular fluid (1\%) ( ). The interrelationships between magnesium and carbohydrate metabolism have regained considerable interest over the last few years (1). Hypomagnesaemia has been linked to poor glycemic control, coronary artery diseases, hypertension, and diabetic neuropathy and foot ulcerations ( ). Magnesium in coronary artery disease is reviewed with regard to its role in the pathogenesis of arteriosclerosis, coronary spasm, myocardial function, acute myocardial infarction and ventricular arrhythmias. Evidence that magnesium depletion may initiate coronary spasm is provided by dog and retrospective human studies. . It is known that an infarcted or ischaemic myocardium loses magnesium and this may be the basis for ventricular arrhythmias. Coronary occlusion in a previously magnesium-depleted heart will result in a larger area of necrosis and ischaemia ( ). Troponin $\mathrm{T}$ is used as a marker for myocardial infarction and its serum value is directly proportional to area of infarction. To elucidate the relationship 
between magnesium levels and area of infarction we compared serum levels of magnesium and Troponin $\mathrm{T}$ in patients admitted with Acute Coronary Syndrome.

MATERIAL AND METHODS: This retrospective study was conducted in Dept of Biochemistry, Christian Medical College, Ludhiana. Forty one patients diagnosed with Acute Coronary Syndrome for whom serum magnesium and Troponin $T$ was requested on the day of admission were taken into the study. Serum Magnesium was processed on Hitachi 902 auto analyzer by a colorimetric assay and Troponin T was processed on Elecsys 2010 by Electrochemiluminiscence. The normal reference values of both parameters with stated methods are given below:-

Magnesium $\quad 1.8-2.6 \mathrm{mg} / \mathrm{dl}$

Troponin T $\quad 0-0.1 \mathrm{ng} / \mathrm{ml}$

The data obtained was processed in Microsoft Excel 2007. Correlation was done by a scatterplot using Pearson correlation coefficient.

RESULTS AND ANALYSIS: Forty one patients admitted with Acute Coronary Syndrome were taken into the study. Their first day serum magnesium and troponin $\mathrm{T}$ values were studied. There were 23 males and 18 females. Mean age of patients was $56.9 \pm 16.7$ years.

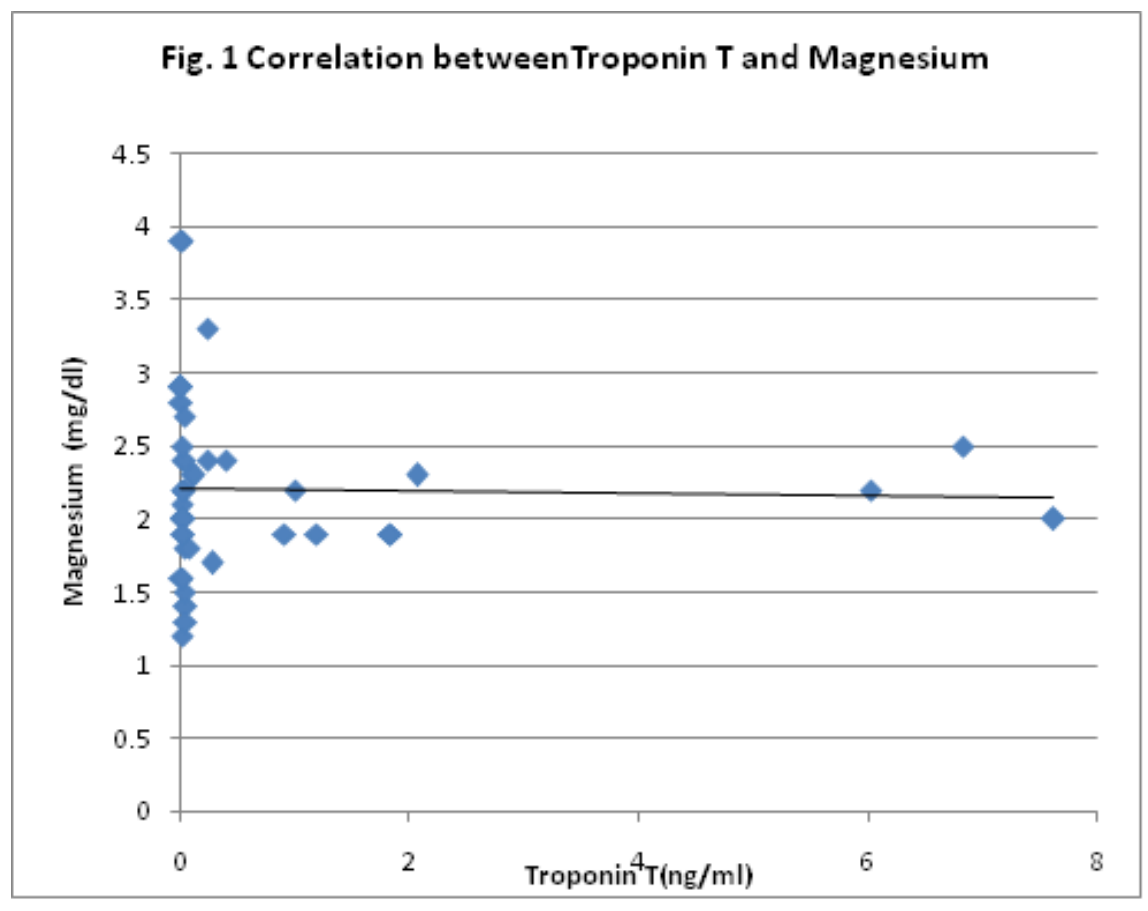

The given scatter plot shows correlation between Troponin $\mathrm{T}$ and Magnesium values in serum of all patients. The relationship between Troponin $\mathrm{T}$ and Magnesium is weekly negative, though not zero.

The Pearson correlation coefficient ' $r$ ' is -0.022

DISCUSSION: data on magnesium supplementation in patients with acute myocardial infarction (AMI) are conflicting. although a number of relatively small randomized clinical trials have demonstrated a remarkable reduction in mortality when magnesium is administered to relatively high risk ami patients, two recently published large-scale randomized clinical trials 
(the fourth international study of infarct survival-isis4 and magnesium in coronaries-magic) failed to show any superiority of intravenous magnesium over placebo ( , ). although many studies have shown that dietary magnesium and serum magnesium have a negative correlation with overall cardiovascular disease, which includes hypertension, dyslipidemia, left ventricular hypertrophy $($,$) , there is one study done on neonates showing a positive correlation with$ magnesium exposure in utero, the reason for this being unknown ( ). Based on this conflicting data the present study was done to see the relationship between low serum magnesium and extent of infarction evident by troponin t values. As shown in figure 1 serum magnesium levels correlate negatively with troponin $\mathrm{t}$ values, although this correlation is very weak.

CONCLUSIONS: The negative correlation between serum magnesium and Troponin $\mathrm{T}$ shown by current study could mean low serum magnesium values may have higher area of infarction. This may be indirectly due to the fact that magnesium is associated with higher severity of comorbid states such as dyslipidemia, insulin resistance, poor glycemic control and affected carbohydrate metabolism. The strength of correlation shown by present study is very weak. Hence, further studies are required to arrive at a definitive conclusion.

\section{REFERENCES:}

1. Elin R. J. Assigment of magnesium status. Clin Chem 1987; 33:1965 - 1970.

2. Gums J G. Clinical significance of magnesium: A review. Drug Intell Clin Pharm 1987; $21: 240-246$.

3. Pham P C, Pham P M, Pham S V et al .Hypomagnesaemia in patients with type 2 diabetes. Clin Am Soc Nephrol 2007; 2:366-73.

4. Iseri LT. Magnesium in coronary artery disease. Drugs. 1984; 28(1): 151-60

5. Shechter M. Body magnesium -the spark of life. Harefuah. 2011 Jan; 150(1):41-5, 67.

6. Shechter M. Does magnesium have a role in the treatment of patients with coronary artery disease? Am J Cardiovasc Drugs. 2003; 3(4):231-9.

7. Houston $\mathrm{M}$. The role of magnesium in hypertension and cardiovascular disease. J Clin Hypertens (Greenwich). 2011 Nov;13(11):843-7

8. Zhang $\mathrm{W}$, Iso $\mathrm{H}$, Ohira $\mathrm{T}$, Date $\mathrm{C}$, Tamakoshi A. Associations of dietary magnesium intake with mortality from cardiovascular disease: the JACC study. Atherosclerosis. 2012 Apr; 221(2):587-95. Epub 2012 Jan 28.

9. Shelton SD, Fouse BL, Holleman CM, Sedor FA, Herbert WN. Cardiac troponin T levels in umbilical cord blood. Am J Obstet Gynecol. 1999 Nov; 181(5 Pt 1):1259-62.

\section{AUTHORS:}

1. Ajay Kumar

2. Shaveta Sagar

\section{PARTICULARS OF CONTRIBUTORS:}

1. Assistant Professor, Department of Biochemistry, Christian Medical College, Ludhiana.

2. Assistant Professor, Department of Biochemistry, Christian Medical College, Ludhiana.

\section{NAME ADRRESS EMAIL ID OF THE CORRESPONDING AUTHOR:}

Dr. Ajay Kumar,

Dept. of Biochemistry, Christian Medical College, Ludhiana - 141008, Punjab.

Email -drajay.email@gmail.com

Date of Submission: 17/07/2013.

Date of Peer Review: 18/07/2013.

Date of Acceptance: 22/07/2013.

Date of Publishing: 24/07/2013 